\title{
Bovine Visceral Schistosomosis Caused By Schistosoma Indicum in Migrant Cattle Slaughtered at Chennai City, Southern India
}

\section{Shivani Mamane}

Madras Veterinary College

Narayanaperumal Jeyathilakan ( $\nabla$ drnjeyathilakan@gmail.com )

Madras Veterinary College https://orcid.org/0000-0002-2367-9808

Bhaskaran Ravi Latha

Madras Veterinary College

T.M.A. Senthilkumar

Tamil Nadu Veterinary and Animal Sciences University

Raja P

Madras Veterinary College

\section{Research Article}

Keywords: Schistosoma indicum, Migrant Cattle, Tamil Nadu, Molecular identification

Posted Date: December 8th, 2021

DOI: https://doi.org/10.21203/rs.3.rs-1116638/v1

License: (c) (1) This work is licensed under a Creative Commons Attribution 4.0 International License. Read Full License 


\section{Abstract}

One hundred and eighty mesentery samples of cattle were collected during a period of October 2019March 2020 for screening visceral schistosomosis from Perambur slaughter house, Chennai, Tamil Nadu, India. Schistosoma indicum was identified in eleven mesenteries of Nellore breed of cattle based on morphology and worm number varied from 1-114 per mesentry. Molecular confirmation based on 16s RNA revealed it to be $S$. indicum. It was found that the infection of $S$. indicum in cattle was first report in Tamil Nadu in last two decades. The slaughtered cattle originated from neighboring states especially Andhrapradesh. The tract of infection needs to be traced accordingly for future control strategies. Awareness must be created among the livestock farmers to prevent production loss due to $S$. indicum infection while purchasing cattle from neighboring states within India.

\section{Introduction}

Bovine Visceral schistosomosis (BVS) is water borne trematode infection which is considered as Neglected Tropical disease. BVS is well recognized as the fifth major helminthosis of domestic animals in the Indian Subcontinent (Sumanth, 2004). This infection is caused mainly by Schistosoma indicum and Schistosoma. spindale in India (Agrawal, 2000). Hence, the species need to be differentiated based on morphology of adult worm tegument and number of testes in male as well as the shape of ova in female (Roy and Tandon,1992; Agrawal, 2012).S. indicum is an obligate parasite of blood vascular system residing in the portal and mesenteric veins of ruminants. The blood fluke infection causes chronic wasting illness and is characterized with haemorrhagic diarrhoea, emaciation, anemia which overlaps with other existing debilitating diseases (De Bont and Vercruyesse, 1998). It also causes reduced milk yield, severe mortality with outbreaks leading to high death rates in cattle (Agrawal, 2012). Diagnostic methods includes direct parasitological examination of ova and miracidium from faeces/rectal pinch which is time consuming and limited in sensitivity since, $S$. indicum ova in cattle are found mostly in the mucous membrane of intestine causing cellular lesions (Krishnamurthi, 1956). In erstwhile Madras province S.indicum infection was uncommon though infrequent and the cases were reported from Kurnool, Chittor and Nellore districts, currently in the state of Andhra Pradesh of India (Alwar, 1950). Mitochondrial markers particularly the species barcoding gene cytochrome c oxidase subunit I (cox I), 16s and 12s ribosomal subunit RNA have been currently used as target gene for species identification and phylogenetics (Jones et al.,2020). The current study was carried out to know the occurrence of BVS due to S.indicum in Chennai, Tamil Nadu, India, which was not recorded since decades and to target species specific 16sRNA for molecular confirmation and phylogenetic studies.

\section{Materials And Methods}

\section{Worm collection}

A total of 180 mesentery samples of cattle were randomly collected during a period of October- March 2020 in order to check active visceral schistosomosis from Perambur slaughter house, Chennai, Tamil 
Nadu, India (Latitude 13.1038 North, 80.2612 East) (Fig. 1). The mesentery was soaked in normal saline to collect the blood flukes present if any for two hours (Fig. 2). Also the veins of the mesentery were punctured under sunlight for recovery of the adult worms by the method of Sumanth et al (2004). The collected worms were subjected to microscopical examination and individually counted to ascertain the intensity of infection.

\section{Morphological identification}

The adult worms were examined for the structural characteristics such as size, tegument, sucker position, gynaecophoric canal, number of testes, and morphology of ova under an inverted microscope at 40X magnification to confirm their identity (Singh, 1958; Srivastava and Dutt, 1962; Agrawal, 2012).

\section{Genomic DNA extraction, PCR and sequencing}

Genomic DNA was isolated from the adult worms using DNeasy Tissue Kit (Qiagen GmbH, Hilden, Germany). The concentration of the genomic DNA extracted was estimated using Biospectrophotometer (Eppendorf, USA). The 16sRNA gene were amplified by thermal cycler using species specific primers (SI16sRNAF-GAGTTTGTAAATGGAGGCTGAG, SI16sRNAR-CCTTATTCAGCCTCTACACCG) previously used by Attwood et al (2007) and Hossain et al (2015). PCR amplification was performed in a total volume of $25 \mu \mathrm{l}$, including $\otimes 110 \mathrm{ng}$ of genomic DNA $(5 \mu \mathrm{l}), 12.5 \mu \mathrm{l}$ of Taq DNA polymerase Red-Dye Master mix (Ampliqon), $10 \mathrm{pmol}$ of each primer $(2 \mu \mathrm{l}$ each) and $3.5 \mu \mathrm{l}$ of nuclease free water. The following amplification protocol was employed in a thermal cycler (BioRad, USA): $95^{\circ} \mathrm{C}$ for 5 minutes (for polymerase activation), followed by 35 cycles each of $95^{\circ} \mathrm{C}$ for 1 minute (denaturation), $52^{\circ} \mathrm{C}$ for 1 minute (annealing) $72^{\circ} \mathrm{C}$ for 1 minute (extension), followed by $72^{\circ} \mathrm{C}$ for 10 minutes (final extension). Negative controls (no DNA template) were included in the PCR reactions which were run in the same thermal cycler. Amplicons were resolved in ethidium bromide-stained agarose gel (1.2\%) and sized by comparison with GeneDirex ® 100 bp DNA ladder as molecular marker. Gels were photographed using Gel Doc 2000 (BioRad, Hercules, CA, USA). Gels were purified and sequenced using the Sanger's method. Their nucleotide sequence analysis was undertaken by BLAST algorithms and databases from the National Centre for Biotechnology (http://www.ncbi.nlm.nih.gov). Phylogenetic tree was constructed using Mega 7.0 software.

\section{Result}

The adult worms examined under the inverted microscope revealed presence of tuberculated body surface in male, presence of oral and ventral sucker in anterior end, male and female found in copulation (Fig. 3), oval shaped ova with terminal spine in uterus (Fig. 4). Based on these characters the worms were morphologically identified as Schistosoma indicum. Among 180 mesenteries, 11 showed presence of $S$. indicum with 6.11 percent infection and worm number varied from 1-114 in number per mesentery. Mixed infection with $S$. spindale was also noticed in 4 mesenteries.

Molecular identification revealed the band size of 606 bp specific for $S$. indicum (Fig. 5). The sequence obtained showed 99.30 per cent homology to $S$. indicum sequence available in Genbank. The sequence 
was submitted to Genbank (accession No.M233263). The phylogenetic tree was constructed using maximum likelihood method with 1000 replicates (Fig. 6 ). The phylogenetic analysis of 16SrRNA of Schistosoma spp. forms four different clades. The first clade comprises of S. spindale, S. indicum and S. nasale. The second clade comprises of S. haematobium, S. bovis and S. curassoni. The third clade comprises of $S$. spindale and $S$. indicum from United Kingdom and India. The fourth clade comprises of S. mansoni and S. indicum. The S. indicum (VPA/MVC/001/M233263) belongs to clade I which comprises of S. spindale, S. nasale and S. indicum from Bangladesh with 99 per cent identity.

\section{Discussion}

Bovine Visceral schistosomosis caused by $S$. indicum is a neglected tropical disease in southeast Asia. This was first discovered in horse, donkey and sheep in north India (Montgomery, 1906). It has also been recorded in cattle, buffaloes, goat and camel. The record of this infection in erstwhile Madras province is not uncommon though infrequent (Rao, 1939;Alwar, 1950). Banerjee et al. (1972) also reported a clinical case of the infection in crossbred Holstein bull in West Bengal based on coprological examination.. In Northern states of India such as Haryana, Himachal Pradesh, Punjab and Rajasthan the incidence rate of S. indicum in cattle was around $2.3 \%$ as per the study conducted by Chaudhri et al, (2007) and it was also noted that the infection of $S$. indicum was more widespread than that of $S$. spindale. Central Indian states also showed this infection in cattle (Giri et al. 2018). Cherian and D'Souza (2009) reported the prevalence of $S$. indicum infection from faecal samples of small ruminants in Karnataka. Prevalence of $S$. indicum in cattle also reported from Kerala (Chirayath, 2007; Divya et al., 2012)

A study conducted by Jeyathilakan et al. (2008) wherein 114 cattle mesenteries collected from same slaughter house in Chennai,Tamil Nadu, were examined among which the prevalence of $S$. spindale was about $30.7 \%$ but there was no $S$. indicum infection found in cattle, even though common intermediate host Indoplanorbis exustus prevalent in Tamil Nadu. The present abattoir study conducted in Chennai revealed the occurrence of S.indicum in Nellore breed of cattle migrated from neighboring Andhra Pradesh state. Identification of Schistosoma spp causing bovine visceral schistosomosis under microscopy can be done by examination of characteristic morphology of ova upon coprological survey but visual appraisal of the affected animal does not aid in diagnosing this condition since the infected animal shows symptoms overlapping with other debilitating diseases. PCR based on 16sRNA gene and sequence analysis has been used for accurate confirmation of the species. Karnataka isolate of S.indicum showed no specific amplification (Manohara et al., 2019)

S. indicum Bangladesh isolate showed $99.30 \%$ identity to the Tamil Nadu isolate. The phylogenetic tree was constructed based on character based method. The pylogenetic tree based analysis indicated that there could have existed a common ancestor for $S$. indicum of India and $S$. cf. indicum W528 Nepal isolate. The common ancestor of Tamil Nadu, India and Nepal isolate could have originated from $S$. spindale of Thailand and Sri Lankan isolate. Gene sequence of Indian isolate of S.indicum was so far not compared with other country isolates ( Jones et al., 2020). However, the earlier report revealed $S$. indicum from India forms a separate clade along with S. spindale of UK origin. 
Livestock sector farmers of Tamil Nadu are unaware of this infection which is prevalent in most of the South Indian states except Tamil Nadu. It was also found that the infection of $S$. indicum was so far not reported from domestic cattle population of Tamil Nadu. This report also showed this infection in slaughtered migrant Nellore cattle breed from neighbouring states of India. The infection was seen more among the adult males and occurred mainly during the monsoons. Further studies are required so that in depth knowledge about epidemiology and bionomics of this infection in other parts of Tamil Nadu can help us to know the clarity of prevalence and take strategic preventive measures in better way.

\section{Declarations}

\section{Funding}

The authors declare that no funds, grants, or other support were received during the preparation of this manuscript.

\section{Conflicts of Interests/ competing interests}

The authors have no relevant financial or non-financial interests to disclose.

\section{Ethics approval}

This is an observational study. The Institutional Animal Ethics Committee, Madras Veterinary College, Chennai, India, has confirmed that no ethical approval is required.

\section{Consent to participate}

Not applicable

\section{Consent for publication}

Not applicable

\section{Availability of data and material}

Not applicable

\section{Code availability}

Not applicable

\section{Author's contribution}

All authors contributed to the study conception and design. Material preparation, data collection and analysis were performed by Dr.Shivani Mamane. Phylogenetic analysis was carried out by Dr. P.Raja. All authors read and approved the final manuscript. 


\section{References}

1. Agrawal,M.C and Southgate, V.R., 2000. Schistosoma spindale and bovine schistosomiasis. Journal of Veterinary Parasitology 14:95-107

2. Agrawal, M. C., 2012. Schistosomes and schistosomiasis in South Asia. Springer India publication.

3. Alwar, V.S., 1950. A note on schistosomes in India with Review of the literature. Madras Veterinary College Annual 8:30-35.

4. Attwood, S.W., Faith, F.A., Fondal, M.M., Alim, M.A., Fadjar, S., Rajapakse, R.P. and Rollinson, D.A., 2007. DNA sequenced based study of the Schistosoma indicum( Trematoda: Digenea) group: population phylogeny, taxonomy and historical biogeography. Parasitology. 134(14): 2009- 2020.

5. Banerjee, K.N., Mookherjee, M. and Gupta, C.K.D.,1972. Incidence of Schistosoma indicum Montgomery. 1906 in a crossbred Holstein bull in West Bengal. Indian journal of Animal Heath 11:56

6. Bedarkar, S.N. and Narladkar, B.W. and Despandae, P.D 2000. Seasonal prevalence of snail borne fluke infections in ruminants of Marathwada region. Journal of Veterinary Parasitology 14:51-54.

7. Chaudhri, S. S., S. Singh and A. Singh, 2007. Epidemiology of hepatointestinal schistosomosis in ruminants of some northern states of India. Indian Journal of Animal Sciences. 77: 288-292.

8. Cherian S.and D'Souza, P.E. 2009. Coprological diagnosis of ovine schistosomiosis by different laboratory techniques. Veterinary world. 2:271-273

9. Chirayath, D., 2007. A study on the prevalence of schistosomiasis in bovines. Intas polivet 8: 143144.

10. De Bont, J. and J. Vercruysee, 1998. Schistosomosis in cattle. Advances in Parasitology 41: 286-363.

11. Divya, S. P., B. Lakshmanan and H. Subramanian, 2012. Prevalence of schistosomosis in cattle. Indian Veterinary Journal. 89(1):81-82.

12. Giri , D. K. , . Kashyap, D. K and. Ramteke, R.C.,2018. Diagnosis and Management of Schistosoma indicum nfestation in a Calf. Intas Polivet, 19 (II): 334-335

13. Hossain, M.S., Begum, N.,Rima, K.U., Dey, A.R. and Khan, A.H.N.L.,2015. Morphologic and molecular investigation of schistosomes from the mesenteric vein of slaughtered cattle. Journal of Agriculture and veterinary science, 8(5): 47-53

14. Jeyathilakan, N., B. R. Latha and S. A. Basith., 2008. Schistosoma spindale in ruminants at Chennai. Tamilnadu Journal of Veterinary and Animal Sciences. 4: 135-138.

15. Jones, B. P., Norman, B. F.,Borrett, H. E., Attwood, S. W., Mondal, M. M. H., Walker, A. J., Webster , J. P ., Rajapakse, R. P. V. J. and Lawton, S. P., 2020. Divergence across mitochondrial genomes of sympatric membersof the Schistosoma indicum group and clues into the evolution of Schistosoma spindale. Scientific Reports (Nature). 10:2480.

16. Krishnamurthi, C.R., 1956. The pathology of Schistosomiasis in animals. Madras Veterinary College Annual. 14:19-23. 
17. Manohara,B.M., Placid,E.D., Mamatha,G.S and Dhanalakshmi, H.,2019. Molecular studies on hepatointestinal schistosomes in cattle. Haryana Veterinarian 58:190-192.

18. Montgomery, P.E., 1906. Observations in bilharziasis among animals in India. Journal of Tropical Veterinary Science 2:138-174.

19. Rao, M.A.N., 1939. A brief review of the species of schistosomes of the domesticated animals in India and their molluscan hosts. Indian Veterinary Journal 15: 349- 358.

20. Roy, B. and Tandon,V., 1992. The surface ultra structural studies of the blood fluke,Schistosoma indicum, a parasite of bovine ruminants. Rivista di Parasitologia, 53: 99-106.

21. Singh, R, N., 1958. Studies on the morphology and life history of Schistosoma indicum, Montgomery, 1906. Journal of the University of Saugar 7: 42-62.

22. Srivastava,H.D. and Dutt, S.C., 1962. Studies on Schistosoma indicum.Indian Council of Agricultural Research Research series 34: 91 pp

23. Sumanth, S., P. E. D'Souza and M. S. Jagannath., 2004. A study of nasal and visceral schistosomiasis in cattle slaughtered at an abattoir in Bangalore, South India. Scientific and Technical Review of the Office International des Epizooties, 23: 937-942.

\section{Figures}




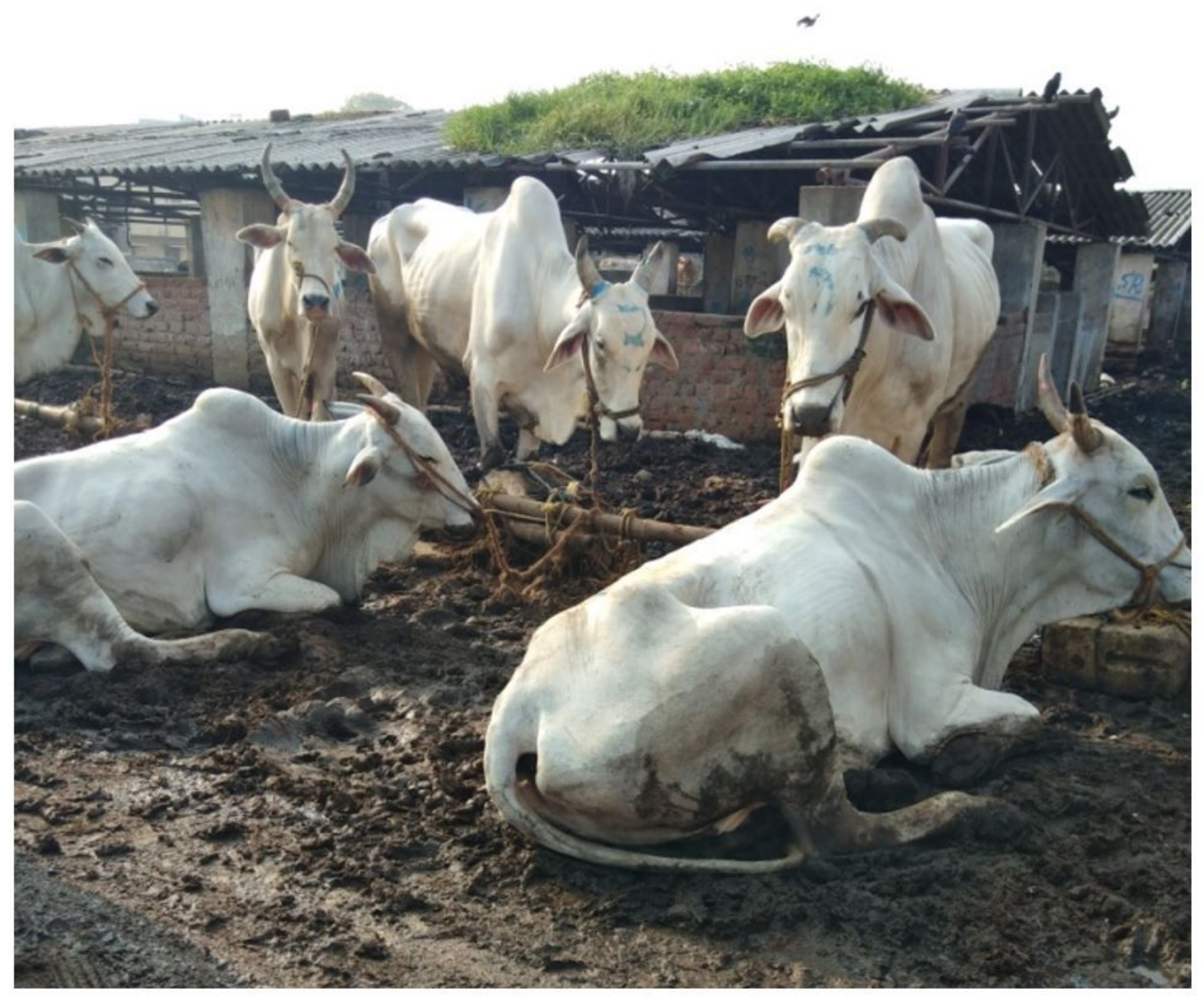

Figure 1

Nellore breed of cattle in lairage of abattoir 


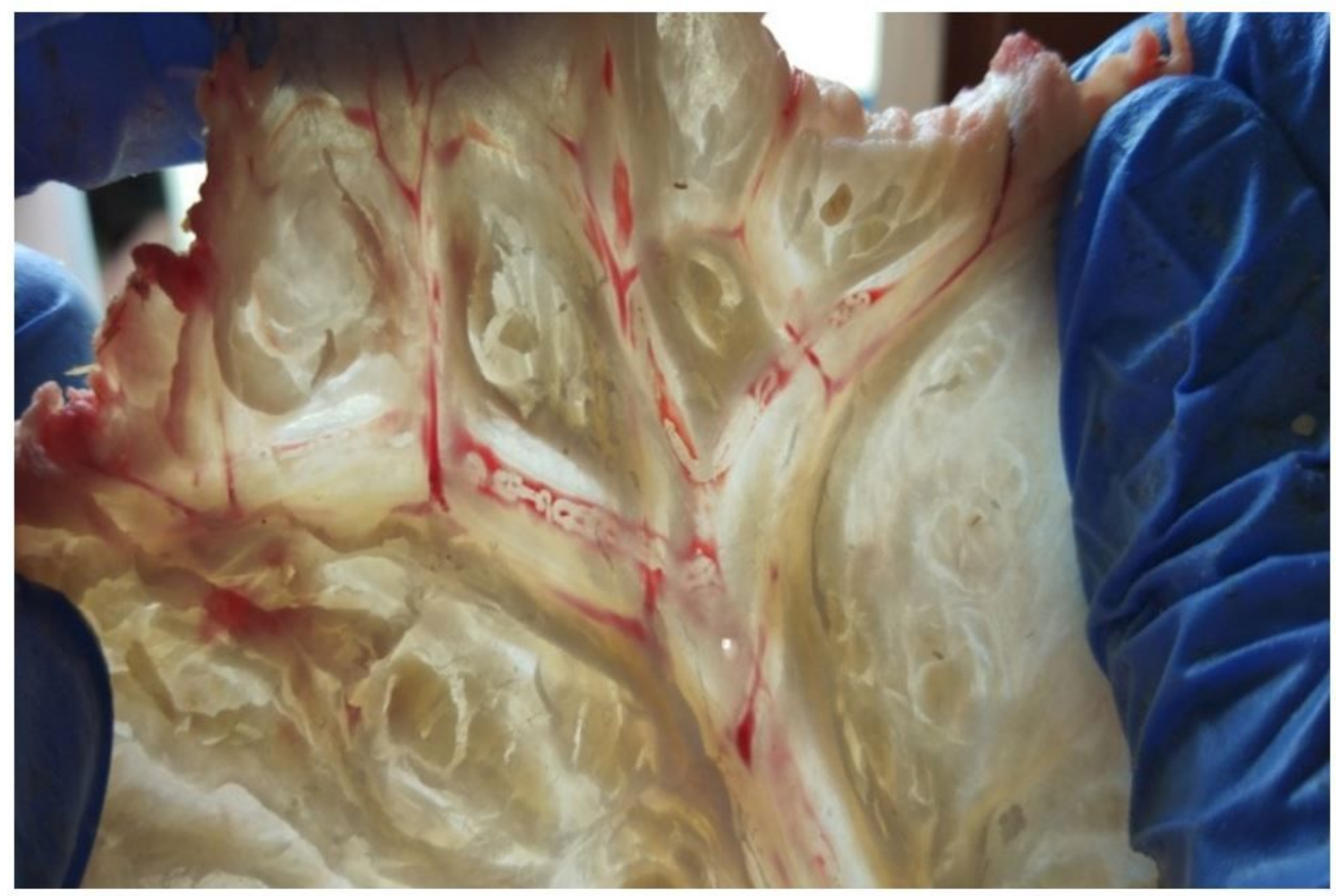

Figure 2

Adult worm in the mesenteric veins of cattle 


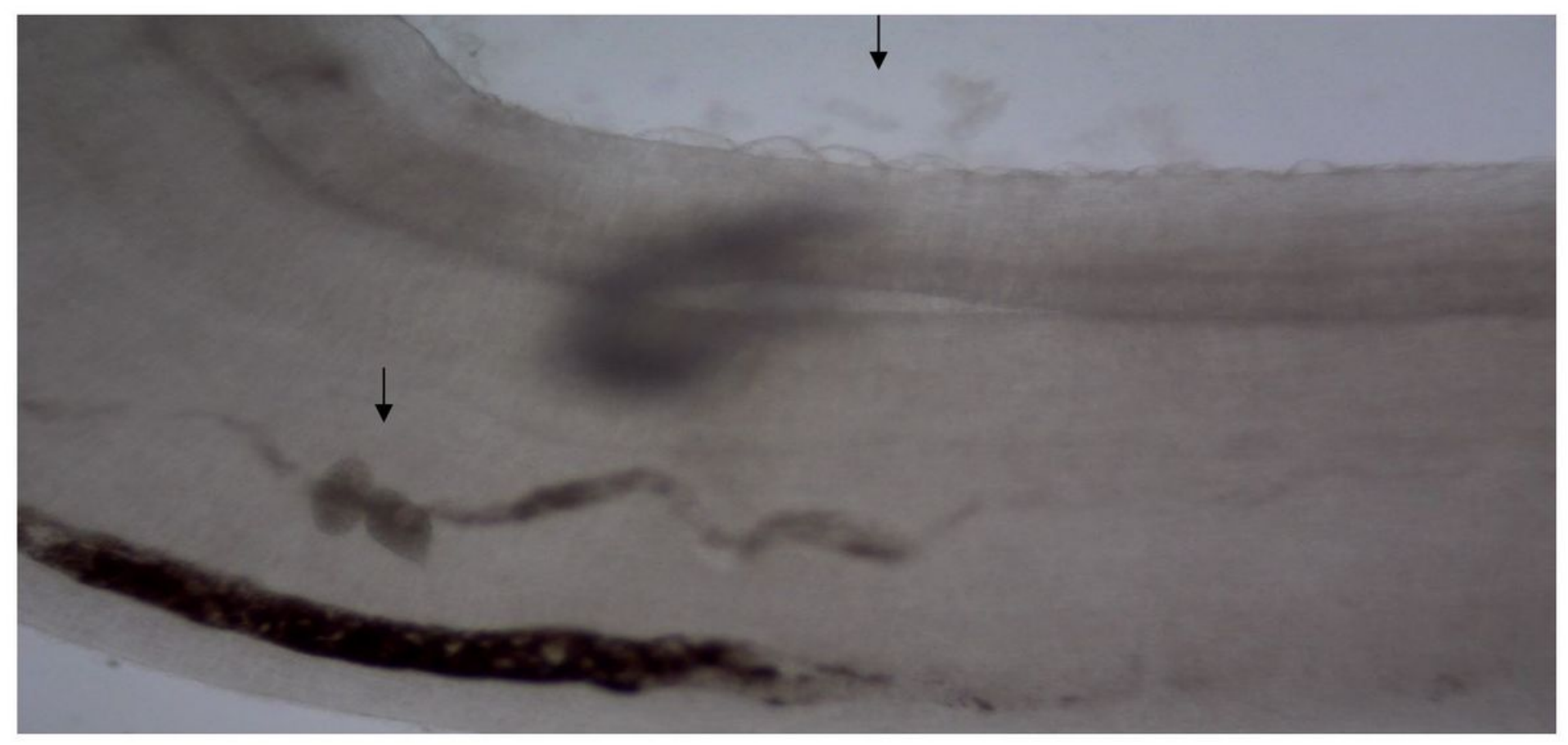

\section{Figure 3}

In copulo adult male and female worm showing tuberculated tegument

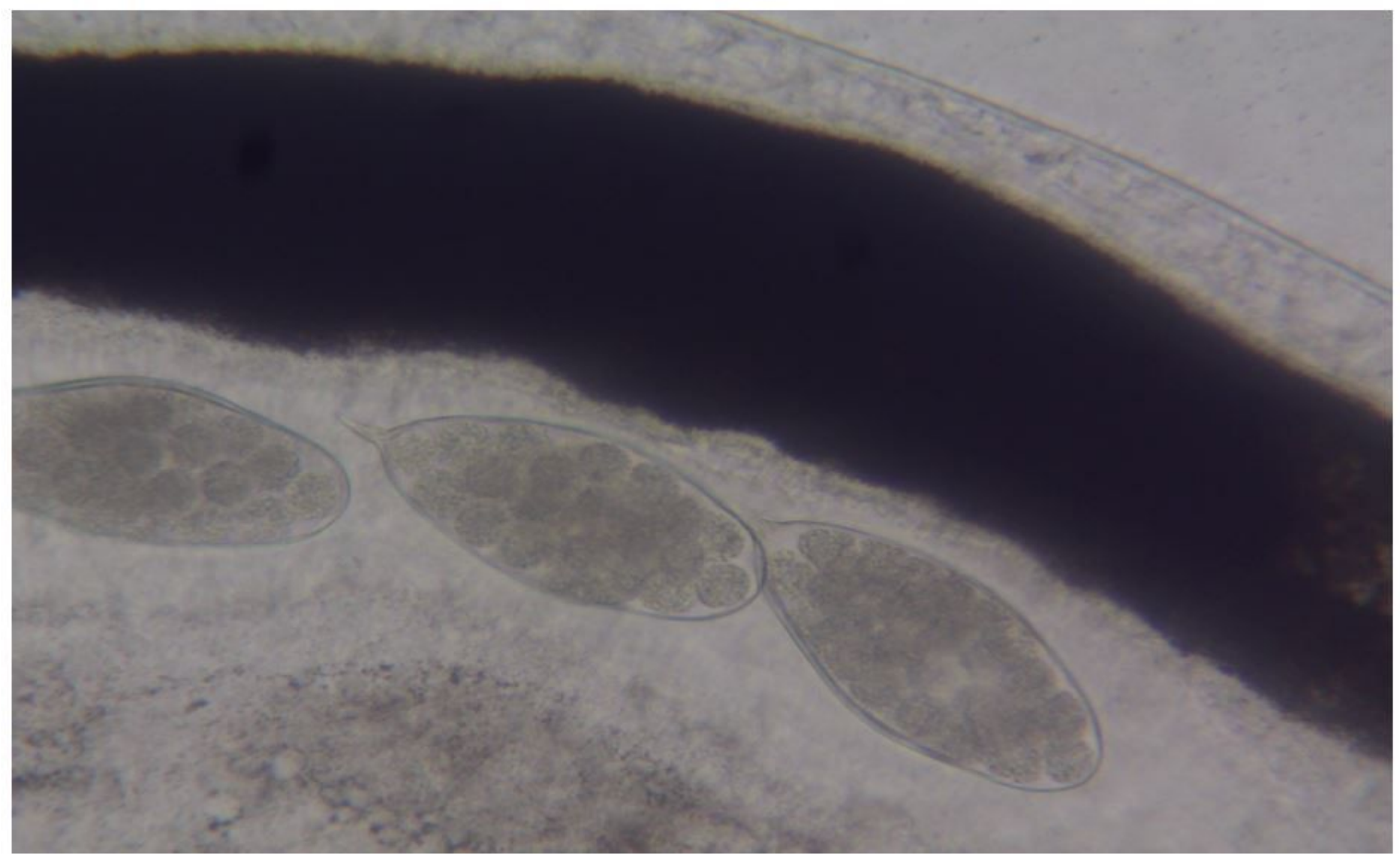

Figure 4 


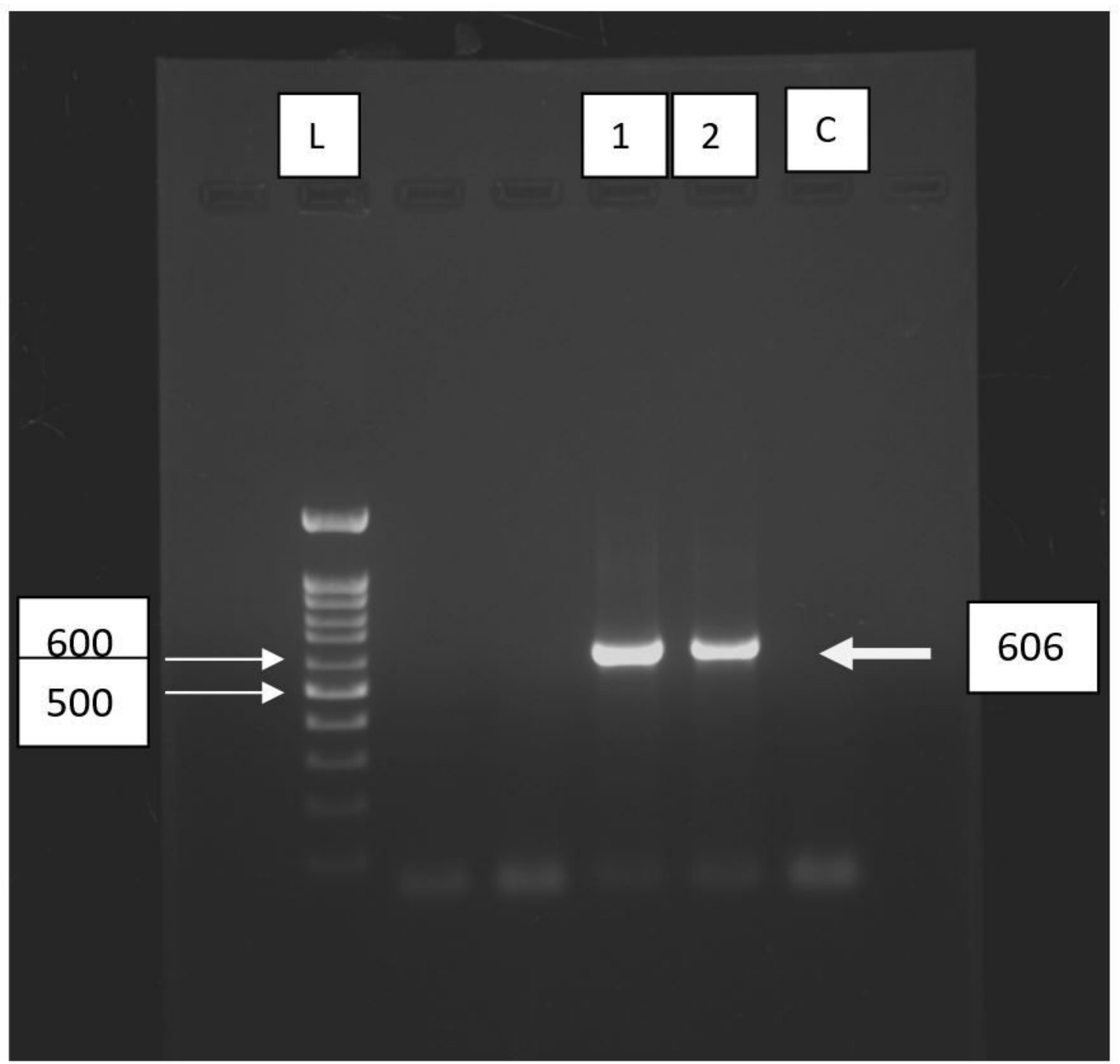

Figure 5

Molecular identification of S. indicum L- 100 bp ladder, lanes 1, 2 positive, C- control 


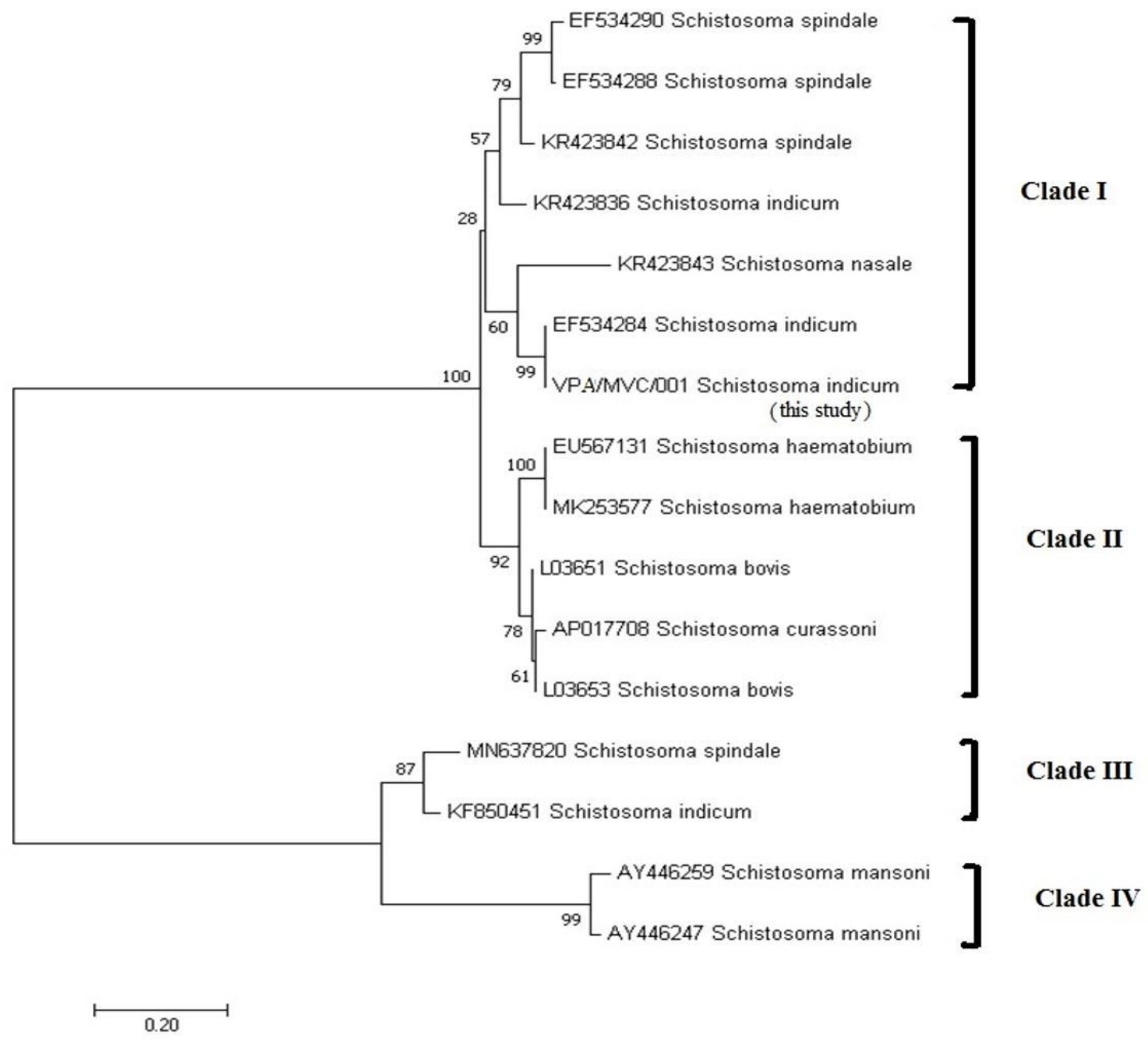

\section{Figure 6}

Phylogenetic analysis of S. indicum based on 16SrRNA gene from Chennai, Tamil Nadu, India 